\title{
The Effect of Multiple Intelligences on DDL Vocabulary Learning
}

\author{
Asma'a Abdulrazzaq Al-Mahbashi (Corresponding author) \\ School of Language Studies and Linguistics, FSSK Universiti Kebangsaan Malaysia, Malaysia \\ E-mail: mahbashiasma@gmail.com \\ Noorizah Mohd Noor \\ School of Language Studies and Linguistics, FSSK Universiti Kebangsaan Malaysia, Malaysia \\ E-mail: nmn@ukm.edu.my \\ Zaini Amir \\ School of Language Studies and Linguistics, FSSK Universiti Kebangsaan Malaysia, Malaysia \\ E-mail: zainir@ukm.edu.my
}

Received: 12-10-2016

Accepted: 05-12-2016

Published: 01-03-2017

\author{
doi:10.7575/aiac.ijalel.v.6n.2p.182
}

Advance Access Published: January 2017

URL: http://dx.doi.org/10.7575/aiac.ijalel.v.6n.2p.182

\begin{abstract}
Over the past decades, the potential for the direct use of corpora known as data driven learning (DDL) has gained great prominence in English language classrooms. A substantial number of empirical studies demonstrated that DDL instruction positively affects students' learning. As learning outcomes can be affected by individual differences, some researchers have investigated the efficiency of DDL in the light of learners' different characteristics to determine the type of learners who were more responsive to DDL. The DDL literature has indicated the need for more research addressing for whom DDL best suits. Therefore, the aim of the current study was to examine whether or not learners' predominant intelligences were significant predictors of DDL learning outcomes. The sample for this study included 30 female EFL Yemeni students at Sana'a University. The study used three primary instruments: a multiple intelligence questionnaire, a posttest and a delayed test on the vocabulary that was taught using DDL. The result of the correlation analyses between the participants' three identified predominant intelligences and their performances in the posttest and delayed test showed an insignificant relationship between the variables. The regression analyses results also revealed that the predominant intelligences insignificantly predicted the participants' posttest and delayed test performances. Based on these findings, learners' needs and preferences should be activated and addressed by classroom instructions for creating a diverse and motivating learning environment.
\end{abstract}

Keywords: corpora, DDL, individual differences, IQ, multiple intelligences

\section{Introduction}

Vocabulary learning is a vital process for the successful acquisition of language, which involves not only students' knowledge of word definitions, but also their attention to different aspects of a word as collocation, synonym and pronunciation, just to name a few (Nation 2005). The integration of computer technology into language teaching is one of the most important developments in foreign language pedagogy (Alsied \& Pathan 2013). Having reviewed the types of technology tools selected for teaching language skills and areas, Stockwell (2007) proclaims that teaching with corpora is one type among several computer technologies that has been used for vocabulary learning.

Since the 13th century, corpus, as a collection of real written and spoken texts, has been a valuable tool for linguistics analysis and language description (McCarthy \& O'Keeffe 2010). Collecting authentic language texts was done manually leading to what is called the era of pre-electronic corpora. As a consequence of computer technology particularly in the late 1960s, a new era of electronic corpus appeared which consequently allowed for "the storage and the analysis of a larger database of natural language than could be dealt with by hand" (Biber et al. 1998:4). The period of the 1960s witnessed the birth of the first generation of concordancer such as the Brown Corpus of Standard American English. In 1980, the second generation of corpora was initiated. Examples of these corpora are the British National Corpus (BNC) and the Corpus of Contemporary American English (COCA) both of which are general corpora compiled from different kinds of written texts as well as spoken transcripts.

While there was an interest in using corpora for linguistic research, communicative language teaching (CLT) appeared to be the dominant approach for foreign language teaching and learning. As indicated by Champers (2010), some applied linguists observed that the use of corpus for studying language and CLT teaching practices share a common feature. Both emphasize the use of authentic materials collected from different sources to provide a high exposure to real target language. This common feature brought about a remarkable achievement by integrating computer corpus in 
English second and foreign language (ESL/EFL) teaching. The application of corpora in language teaching and learning dates back to the 1990s (McEnery \& Xiao 2011). When a corpus is integrated in the classroom, (a) learners become autonomous and they construct their learning by exploring corpus data, (b) a concordancer provides examples from which learners can draw their answers, (c) the organization of texts in the concordance program makes learners more aware of language points, and (d) the integration of corpora in the classroom is based on an approach known as data driven learning (DDL) (Sripicharn 2002).

The clear distinction among learners in their achievements of second and foreign language learning has stimulated a tremendous interest in individual differences research over the last decades (Gan 2011). The variability in students' performance found in the same learning environment can be attributed to their individual learning differences (Lightbown \& Spada 2006). Hence, learners' characteristics such as age, attitude, motivation, anxiety, multiple intelligences, learning strategies and learning styles are considered factors that play a major role in instruction. To illustrate, a teaching instruction has a different impact on learners which is more likely to be due to their different characteristics. These characteristics, as Jonassen and Grabowski (2011: viii) state, serve as "filters or lenses" of instruction that can reveal students' response to that instruction and predict their learning outcomes which in turn assists in modifying the instruction and designing more effective teaching materials adjusted to the needs of learners. As far as DDL is concerned, Boulton and Tyne (2013) pointed to the need of exploring differences in learners' DDL performances that individual learning can explain. Therefore, this study investigated the role of multiple intelligences as one of the individual differences that has not been examined in relation to students' DDL learning outcomes.

\section{Literature review}

\subsection{The Direct Use of Corpora: DDL}

Over 20 years ago, Johns (1990) coined the term DDL to describe the use of corpora in the language classroom by which learners are exposed to real language texts driven by a corpus. DDL is defined as, "a method in which learners read large amounts of authentic language and try to discover linguistic patterns and rules by themselves" (Talai \& Fotovatnia 2012:1526). It is used as an inductive method of learning which requires learners to analyze, make hypothesis and draw conclusions from corpus data. In this method, instead of being taught to, learners can interact with corpora either directly (corpora hard version) or be given paper-based corpus activities prepared by their teachers (corpora soft version). ESL/EFL language teachers or learners can search for a target word or a phrase by typing that word in a concordance program that then generates all instances of the examined word in natural contexts. The target word is presented in a keyword-in-context (KWIC) format, where each occurrence of the target word is displayed in a single row and the target word is highlighted and placed in the middle. For instance, Figure 1 illustrates the KWIC occurrences of the word "effort" extracted from COCA.

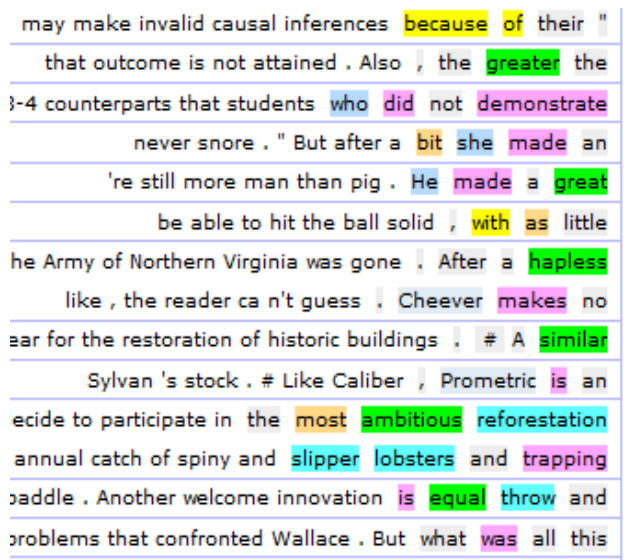

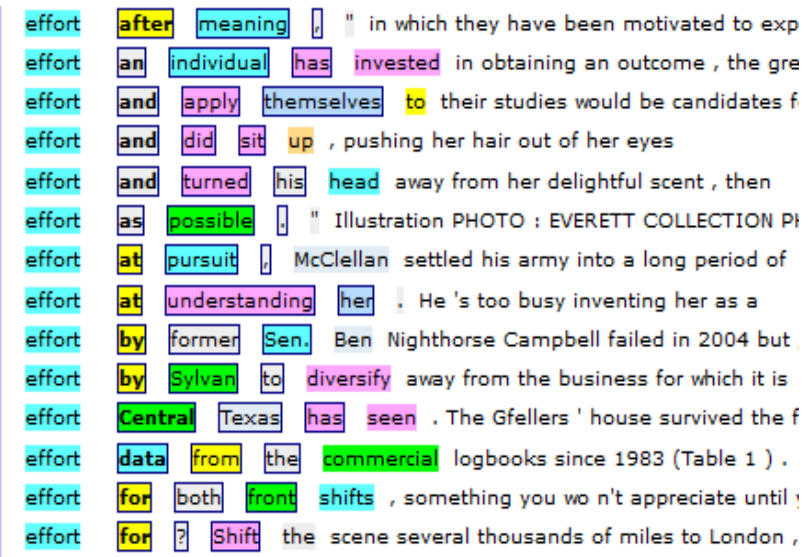

Figure1. Effort in KWIC

The use of corpora can also offer a collocation search. Figure 2, shows the different adjective collocations of the target word with their frequencies just by first typing the word effort in the "word" box and then selecting the desired part of speech from the "POS list" tag, e.g. adjective. Making a click on any of the collocations, such as the word necessary, displays many texts of the key word as seen in Figure 3.

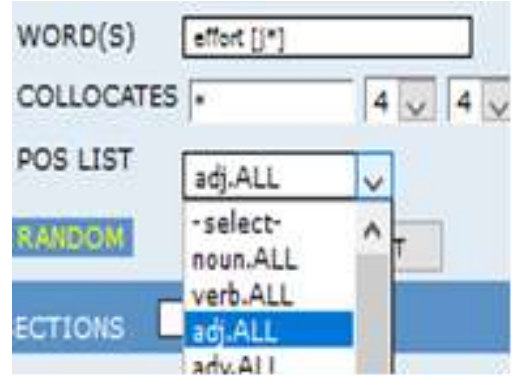

\begin{tabular}{|c|c|}
\hline cares & $\Rightarrow E Q$ \\
\hline HECEESAEYY & 37. \\
\hline 1MOCED & 35 \\
\hline MUSE & $2:$ \\
\hline WOSTHWOE & 12 \\
\hline E.GPY & $\Xi$ \\
\hline NUSES & $\mathrm{E}$ \\
\hline
\end{tabular}

Figure 2. Collocate Search for Effort 


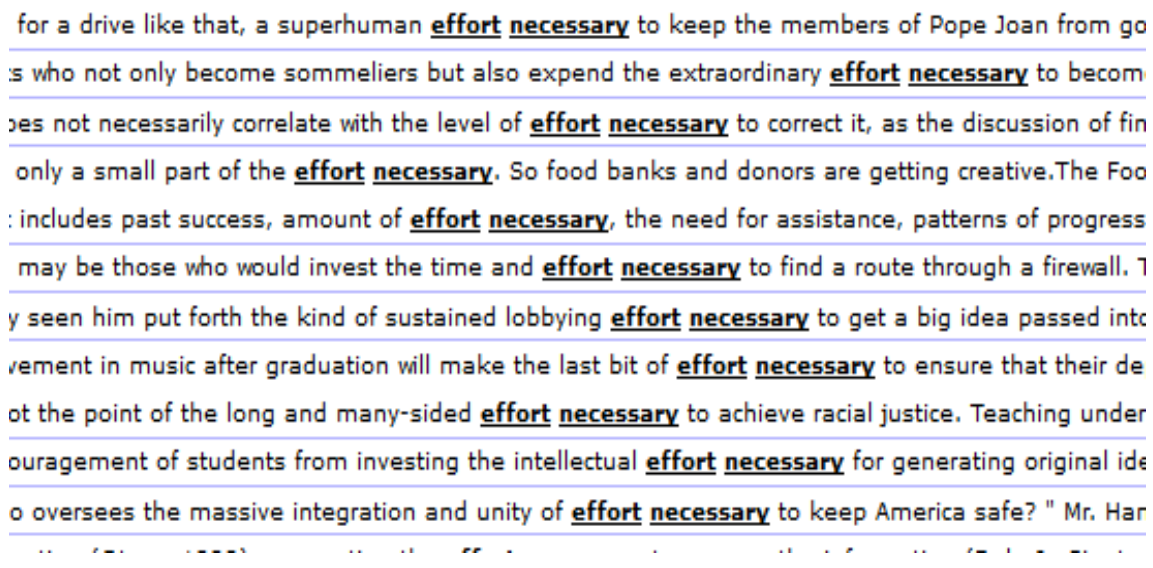

Figure 3. A Collocation Word of Effort

DDL brings distinct advantages that have not been offered by traditional methods of teaching and learning. For Oghigian and Chujo (2010), one of the major advantages of DDL is the authentic language generated from a corpus. It has been acknowledged that the use of authentic materials raises learners' motivation, renews their interest in the subject and enables them to make a connection between the language in the classroom and the real world outside the classroom (Al Azri \& Al Rashidi 2014). As for learning vocabulary, Ghadirian (2002) highlights that multiple exposures to words are essential for effective vocabulary learning. It has also been indicated that learning vocabulary is not only restricted to learning dictionary definitions but also involves learning different vocabulary aspects including knowledge of collocations (Nation 2005). The use of DDL allows for frequent encounters of newly learned words in various contexts. Unlike dictionaries that present limited exposures to collocations, learners' vocabulary knowledge of collocations could be enhanced in DDL classroom by using a corpus, producing many collocates of a particular word in different contexts along with their frequencies (Donesch-Jezo 2013).

\subsection{Individual Differences In The DDL Classroom}

Variations in learners' performance achieved through the same teaching method imply that there is no single method that can work well for all learners. Boulton (2011) asserts that no method is equally effective with diverse learning needs and abilities. As learners' characteristics have an effect on learning performance, individual differences among learners become important considerations that should be taken when applying teaching techniques. As far as DDL is concerned, some studies investigated the role of individual differences in learners' DDL learning outcomes to explore the kind of learners who benefited more from the DDL method. Starting with students' learning styles (inductivedeductive), Lee and Liou (2003) incorporated DDL in a Taiwanese high school classroom with forty-six students. The posttest results revealed that the inductive group performed better than the deductive group. Chan and Liou (2005) designed five web-based units to improve university learners' knowledge of different types of verb-noun collocations. The participants were taught three assigned units with a bilingual concordance program, but they received direct explanations on the target collocation patterns and completed some activities for learning the other two units. Before the treatment, the participants filled out a questionnaire concerning their preferences for deductive or inductive teaching methods. The effect of the participants" learning styles on their posttest and delayed tests performances was not definite. As Chan and Liou (2005: 241) remarked, "students did not show significant preference of either one of the methods" and, in general the use of concordances significantly promoted their short-term and long-term achievements more than learning without concordances.

Researchers (e.g., Lee and \& Liou, 2003, Tian 2005, Chan and \& Liou, 2005) examined whether students' proficiency levels have a relationship with DDL treatment effects. The studies conducted by Lee and Liou (2003) and Chan and Liou (2005) involved a number of participants who were divided respectively into vocabulary level groups: high, intermediate and low, and into collocation knowledge groups: high and low. The differences between the pre and posttest results of the groups indicated that low-level students benefited more from DDL instruction than high-level students. However, in Tian's (2005) study, DDL was used to enhance three different language aspects including grammar, word usage and text features type. The DDL group worked on paper based corpus while the control group was taught with the use of traditional teaching methods. Based on their responses to a general English proficiency test, the participants in the two groups were categorized into high and low levels. A comparison of the gain scores results obtained by the DDL high group level and the low group level demonstrated that DDL did not have a significant, different effect on either group's proficiency level. The last examined individual difference was attitude. In a study by Chan and Liou (2005), attitudes towards using DDL in students' learning of collocation were correlated with their performances after their exposure to bilingual corpus activities. The results indicated that students who liked using the corpus tool and who found that the translation into their L1 language helped while doing corpus-based exercises obtained higher scores in the retention test. 


\subsection{Multiple Intelligences}

The twentieth century witnessed a development of the first intelligence test known as intelligence quotient (IQ) developed by Binet and Simon in 1905. The IQ test intended to measure the linguistic and mathematical abilities of children in Paris in order to predict their success and failure in schools. Based on their IQ scores, learners were divided into two groups: successful learners with strong linguistic and mathematical cognitive abilities and unsuccessful learners who lacked such capacities. Those who possessed linguistic and mathematical intelligence enjoyed a privilege of having taken extra courses focusing on critical thinking and calculation over their counterpart, unintelligent learners. The test provoked some criticism from psychologists as being culturally biased in favor of only the Westerners. It was also criticized for assessing only linguistic and mathematical skills while neglecting learners' different skills (Rahimi at al. 2012).

As the single fixed view of intelligence was subjected to criticisms, a new conceptualization of intelligence emerged. The new notion expanded intelligence to comprise different abilities. The leading proponent of the view of multiple intelligences was Howard Gardner. Gardner (1983) introduced the theory of multiple intelligences. According to this theory, intelligence is "the capacity to respond successfully to new situations - to tackle a task demanded by life" (Gardner 1983:8). The term "multiple" puts a great emphasis on the existence of different cognitive abilities and the word "intelligences" underlines the equal importance of these potentials as the linguistic and the mathematical abilities determined by the IQ test. The pluralistic view of intelligences covers a combination of eight intelligences existing with different levels of development within each individual. These eight domains are presented in the following:

- Verbal-linguistic intelligence (word smart): It is the most common intelligence that involves an effective use of the written and spoken forms of a language (Baş \& Beyhan 2010). Learners with highly developed verballinguistic intelligence always think in words. They enjoy activities such as storytelling, reading, word games, discussion, writing and speaking.

- Logical-mathematical intelligence (numbers smart): It is the ability to use inductive reasoning and to solve problems in logical and systematic ways (Dung \& Tuan 2011). Logical mathematical learners enjoy activities such as crossword puzzles, ordering and matching.

- Spatial-visual intelligence (picture smart): It is the capacity to create mental or physical images for spoken, reading, or written language and the ability to manipulate them (Gardner 1983). Learners with this intelligence learn best through drawing, watching movies, matching and describing pictures.

- Bodily-kinesthetic intelligence (body smart): It is the ability to use one's body to solve problems (Baş \& Beyhan 2010). Learners with strong bodily-kinesthetic intelligence enjoy physical activities such as roleplaying and hands-on activities.

- Interpersonal intelligence (people smart): Gardner (1983) defined this type of intelligence as the ability to understand others' feelings, needs and thoughts and work with them effectively. Interpersonal intelligence activities include teamwork exercises and group discussion.

- Intrapersonal intelligence (self-smart): It involves self-knowledge and self-awareness (Dung \& Tuan 2011). Intrapersonal intelligence learners are self-dependent who like to work alone. Thus, they enjoy activities such as reflective learning activities and individual projects.

- Musical intelligence (music smart): It is one's ability to perceive and recognize tones and rhythms. It also involves sensitivity to musical environments (Moran et al. 2006). Musical intelligence learners can be involved in tasks that require them to play an instrument, sing and write lyrics.

- Naturalistic Intelligence (nature smart): It is defined as the ability to "distinguish and categorize objects or phenomena in nature" (Moran et al. 2006:25). In the language classroom, categorizing vocabulary according to theme and field trips are some activities that cater to naturalistic learners.

Human intelligences are flexible constructs that can be developed through training, practice and environmental supports. McKenzie (2002) classified the above eight intelligences into three domains: logical, musical and naturalistic intelligences are categorized as an analytic domain, while linguistic, interpersonal and kinesthetic intelligences are characterized as an interactive domain and intrapersonal and visual intelligences are considered as an introspective domain. The analytical domain intelligences require learners to be engaged in analyzing the learning process, whereas the interactive domain intelligences emphasize learning through interaction, and learning by the introspective domain intelligences is achieved through the individual's reflection on his/her experience and belief.

As mentioned earlier, this study intends to explore whether Yemeni EFL students' multiple intelligences, as one of the individual differences left unexamined, relates and contributes to their DDL performance. It must be indicated that this study is a continuation of two previous studies by Almahbashi, et al. (2015a, 2015b). The first study revealed the degree to which EFL Yemeni students possessed the eight intelligences. Based on the intelligence profile results, three predominant intelligences were used in designing DDL activities. The DDL activities were essential for the second empirical study that investigated the effect of DDL on developing Yemeni EFL students' definitional and collocation receptive knowledge. 


\section{Methodology}

\subsection{Context of the Study}

The context of the current study was the same context reported by Almahbashi, et al. (2015a) and (2015b) as this paper is part of those studies. This research was conducted at Sana'a University, in the English Department of Education Faculty during the first semester 2014-2015.

\subsection{The Sample of the Study}

The participants of the study were the 30 female Yemeni EFL learners who participated in Al-mhabshi, et al. (2015a) and was also the DDL group in Al-mahbahsi, et al. (2015b).

\subsection{Research Instruments and Procedure}

\subsubsection{Multiple Intelligences questionnaire}

To achieve the purpose of this study, the instruments used in Almahbashi, et al. (2015a, 2015b) were necessary. Almahbashi, et al. (2015a) adapted McKenzie's (1999) MI inventory that is based on Gardner's (1983) multiple intelligences. The inventory consists of 80 statements that cover the eight intelligences. The questionnaire was administered to the participants in their reading course class. They had to indicate (1) for the statements that described themselves. The result revealed that mathematical-logical, visual-spatial and interpersonal intelligences were the highly developed intellectual abilities among the DDL group participants.

\subsubsection{Posttest- delayed posttest}

In Almahbashi, et al. (2015b), paper-based corpus materials were designed on the basis of the three predominant intelligences. The DDL group was engaged in activities that covered 30 academic words with two of their most frequent collocations. Four weeks after the intervention, the participants were tested on their knowledge of the taught words using a posttest. The participants' knowledge of word meanings was first examined adapting Paripakhat's and Wesche's (1993) vocabulary knowledge scale (VKS). The participants had to choose either, "I do not know the meaning of this word" or, "I know the meaning. It means....". Those who knew the meaning of a target word had to choose its correct collocation from alternatives. The delayed test had the same structure of the posttest and it was administered a month after the posttest distribution. The findings showed the mean scores of the participants' posttest $(M=17.16)$ as well as delayed test $(M=19.18)$ performance.

\section{Data Analysis}

After obtaining the results from the MI questionnaire and the two sets of tests, the Pearson correlation coefficients were used to assess the connection between the dependent variables of the posttest and delayed test scores of the DDL participants with their three high developed intelligences as independent variables. The Pearson correlation analysis included the coefficient of determination ( $\mathrm{r}$ ) to measure the direction of the relationship between the variables and the value of significance (p) for assessing the significance of the relationship that is determined to be significant when $\mathrm{P}<.05$. In addition, regression analyses were employed to determine the intelligence that served as the best predictor of the participants' DDL learning outcomes and to estimate its significant effects.

\section{Result and Discussion}

\subsection{The Effect of the Dominant Intelligences on DDL Posttest Outcomes}

The Pearson correlation coefficients were calculated to determine the association between the participants' posttest scores and their more developed intelligences. The first correlation was conducted to see if a significant relationship existed between the DDL group's mathematical-logical intelligence and their posttest performance. Table 1 shows the Pearson correlation coefficients computed between the two variables.

Table1. Correlation between mathematical-logical intelligence and posttest scores

\begin{tabular}{clc}
\hline & & Posttest scores \\
\hline \multirow{2}{*}{$\begin{array}{c}\text { Mathematical-logical } \\
\text { intelligence }\end{array}$} & Pearson Correlation & .313 \\
\cline { 2 - 3 } & Sig. (2-tailed) & .092 \\
\hline & $\mathrm{N}$ & 30 \\
\hline
\end{tabular}

* Correlation is significant at the 0.05 level (2-tailed).

As seen in Table 1, there was a positive relationship between mathematical-logical intelligence and the posttest performance. Meaning, as the learners' mathematical intelligence increases so does their performance. However, the $p$ value of $.092(\mathrm{p}>0.05)$ suggests that this relationship was not significant. Thus, the participants' performance in the posttest is not significantly correlated with their mathematical-logical intelligence.

The correlation result between the second dominant intelligence, visual-spatial intelligence, and the participants' posttest test scores is displayed in Table 2. 
Table 2. Correlation between visual-spatial intelligence and posttest scores

\begin{tabular}{lcc}
\hline & & Posttest scores \\
\hline Visual-spatial & Pearson Correlation & 366 \\
\cline { 2 - 3 } intelligence & Sig. (2-tailed) & .070 \\
\cline { 2 - 3 } & $\mathrm{N}$ & 30
\end{tabular}

* Correlation is significant at the 0.05 level (2-tailed).

Table 2 revealed that there was insignificant positive correlation between the participants' scores and visual-spatial intelligence $(r=366, p>0.05)$. The last correlation was determined between the posttest scores and interpersonal intelligence. As shown in Table 3 below, there was a negative association between the participants' interpersonal intelligence and their posttest scores. The direction of the coefficient's value $r=-.145$ suggests that the higher the students' level of interpersonal intelligence, the lower their performance would be. Nevertheless, the correlation analysis yielded no significant correlation between the two variables $(\mathrm{P}>0.05)$.

Table 3. Correlation between interpersonal intelligence and posttest scores

\begin{tabular}{lcc}
\hline & & Posttest scores \\
\hline \multirow{2}{*}{$\begin{array}{l}\text { Interpersonal } \\
\text { intelligence }\end{array}$} & Pearson Correlation & $-.154-$ \\
\cline { 2 - 3 } & Sig. (2-tailed) & .417 \\
\cline { 2 - 3 } & $\mathrm{N}$ & 30 \\
\hline
\end{tabular}

* Correlation is significant at the 0.05 level (2-tailed).

Besides using Pearson correlation analysis, multiple regressions were employed in an attempt to determine which of the three intelligences as independent variables, were predictive of the participants' performances after their exposure to the DDL method. A summary of stepwise multiple regressions results are presented in Table 4.

Table 4. Summary of multiple regressions between the dominant intelligences and the posttest performance

\begin{tabular}{cccc}
\hline Variables & Beta & $\mathrm{T}$ & $\mathrm{P}$ \\
\hline Mathematical-logical intelligence & .257 & 1.45 & .157 \\
\hline Visual-spatial intelligence & .317 & 1.80 & .083 \\
\hline Interpersonal intelligence & -.155 & -.894 & .379 \\
\hline
\end{tabular}

The output of the regressions analyses above showed that visual-spatial intelligence has the highest effect; for one standard deviation increase in the participants' visual-spatial intelligence, there will be .317 of standard deviation increase in their performance. However, this effect did not reach a significant level ( $p>.05)$. Similarly, mathematicallogical and interpersonal intelligences did not have an important effect as the significant value of each was ( $p>0.05$ ). Accordingly, the three independent variables were not predictors of students' performance.

\subsection{The Effect of the Dominant Intelligences on DDL Delayed Test Outcomes}

Correlation analysis was also conducted to see if there was a relationship between the participants' delayed test scores and the three identified high-level intelligences. The details of the correlation analysis between the test scores and mathematical-logical intelligence are displayed in Table 5.

Table 5. Correlation between mathematical-logical intelligence and delayed test scores

\begin{tabular}{ccc}
\hline & & delayed test score \\
\hline \multirow{2}{*}{$\begin{array}{c}\text { Mathematical } \\
\text { intelligence }\end{array}$} & Pearson Correlation & .160 \\
\cline { 2 - 3 } & Sig. (2-tailed) & .398 \\
\cline { 2 - 3 } & $\mathrm{N}$ & 30 \\
\hline
\end{tabular}

* Correlation is significant at the 0.05 level (2-tailed).

The data presented in Table 5 revealed a non-significant relationship between mathematical-logical intelligence and students' delayed performance $(\mathrm{r}=.160, \mathrm{p}>0.05)$. Similarly, as shown in Table 6 , visual intelligence did not significantly correlate with the delayed test scores $(\mathrm{r}=.212, \mathrm{p}>0.05)$.

Table 6. Correlation between visual-spatial intelligence and delayed test scores

\begin{tabular}{ccc}
\hline & & delayed test score \\
\hline \multirow{2}{*}{$\begin{array}{c}\text { Visual-spatial } \\
\text { intelligence }\end{array}$} & Pearson Correlation & .212 \\
\cline { 2 - 3 } & Sig. (2-tailed) & .261 \\
\cline { 2 - 3 } & $\mathrm{N}$ & 30
\end{tabular}

* Correlation is significant at the 0.05 level (2-tailed). 
The relationship between interpersonal intelligence and the participants' delayed scores was comparable to the relationship between the two other previously examined intelligences and the delayed test scores. The correlation analysis result shown in Table 7 below indicates that there was an inverse but insignificant relationship between interpersonal intelligence and the delayed test performance $(r=-.010, \mathrm{p}>0.05)$.

Table 7. Correlation between interpersonal intelligence and delayed scores

\begin{tabular}{ccc}
\hline & & \multicolumn{2}{c}{ delayed test score } \\
\hline \multirow{2}{*}{$\begin{array}{c}\text { Interpersonal } \\
\text { intelligence }\end{array}$} & Pearson Correlation & -.010 \\
\cline { 2 - 3 } & Sig. (2-tailed) & .958 \\
\hline * Correlation is significant at the 0.05 level (2-tailed).
\end{tabular}

Multiple regressions were also used to determine the predictive power, if any, of the three dominant intelligences on the participants' delayed test achievements. Table 8 shows the $\beta$ value for mathematical-logical, visual and interpersonal intelligences as $125,189,-.010$ respectively with a $\mathrm{p}$ value $>0.05$, indicating that these independent variables did not have a significant contribution to the participants' performance.

Table 8. Summary of multiple regressions between the dominant intelligences and delayed test performance

\begin{tabular}{lccc}
\hline Variables & Beta & $\mathrm{T}$ & $\mathrm{P}$ \\
\hline Mathematical-logical intelligence & 125 & .647 & .523 \\
\hline Visual-spatial intelligence & 189 & .975 & .338 \\
\hline Interpersonal intelligence & -.010 & -.055 & .957 \\
\hline
\end{tabular}

The correlation and regression results revealed that none of the predominant intelligences was connected with and predicted students' achievements in the posttest and delayed test. Based on the correlations results, mathematicallogical intelligence had a positive relationships with the participants' posttest and delayed test scores $(\mathrm{r}=.313, .160)$. These positive connections could be attributed to the fact that DDL techniques are closely matched to mathematicallogical intelligence. In other words, DDL is an inductive method that encourages discovery and problem-solving learning and logical students have the ability to work on problem solving activities and use inductive reasoning (Dung \& Tuan 2011). In addition, the relationship between visual-spatial intelligence and the tests results also proved to be positive $(r=.336, .212)$. This can be explained by the nature of visual spatial learners who enjoy discovery learning (Greenfild 2009), besides being able to think in pictures. For interpersonal intelligence, it was negatively linked with the tests scores $(\mathrm{r}=-.154,-.010)$. Though DDL classroom promotes interaction among learners (Çelik \& Elkatmiş 2013) and it accommodates interpersonal intelligences students' needs, one of the negative sides of cooperative learning is the little attention learners pay to the learning environment. In this study, some learners did not focus on the DDL activities. They were observed to be speaking in Arabic and talking about personal matters rather than focusing on the content of the activities. In addition, during pairs and group works, the researcher went around the class to check the work progress of the students and to encourage all to work on the allotted tasks. However, as observing all the pairs or groups at once is impossible, it is more likely that some students who are probably lazy or weak kept quiet depending on their group members or partners to do the work.

Nevertheless, the correlation analyses also showed that the associations between the three predominant intelligences and the DDL group's performance on the posttest and the delayed test were statistically insignificant $(\mathrm{p}>0.05)$. That was supported by the regression results which showed that the three intelligences were not significant predictors of the participants' tests scores. These findings are consistent with the results of previous studies conducted by Biria et al. (2014) and Farahani and Kalkohran (2014) which demonstrated an insignificant relationship between the three intelligences and EFL students' vocabulary learning. However, the results of the current study are inconsistent with Zarie's and Asfhar's (2014) results which found a significant positive relationship between visual-spatial intelligence and vocabulary learning and also revealed that this intelligence accounted for $20 \%$ of variance in vocabulary knowledge.

The insignificant effect of mathematical-logical, visual-spatial and interpersonal intelligences on the DDL learning outcomes could be attributed to the less activation of these intelligences in the participants' university context. The result from the MI questionnaire as presented in Almahbashi et al. (2015a) showed that these intelligences were the high developed ones. The English text books at Yemeni schools could have an essential effect on developing mathematicallogical intelligence and visual intelligence as the schools books included many activities accommodated the two intelligences. Regarding interpersonal intelligence, authoritative parents' style could help in enhancing interpersonal skills of children and adult which might be used with the participants of the study (Almahbashi et al. 2015a). However, when joining university, Yemeni EFL learners' potential and needs are not addressed. They are only receivers of 
information who merely listen to lectures and then use rote memorization to demonstrate what they learned (Muthanna \& Karaman 2010). In this study, though the DDL activities were designed based on the participants' three predominant intelligences, the time the DDL participants spent on these activities which was only a month were not enough to activate these intelligences.

For intelligences to have an effect on learning outcomes, Tajeddin and Chiniforoushan (2011) emphasized the need for activating intelligences by increasing students' engagement in learning activities relevant to their MI strengths. To put it differently, the insignificant contributions of learners' intelligences on their performance necessitates a significant change in teaching practices that should take into consideration learners' needs. The best way to do so is to integrate multiple intelligences into EFL classroom. Christison (1996) cited in Saeidi (2009) suggested some steps for multiple intelligences to be implemented including: (1) categorizing classroom activities according to learners' multiple intelligences profile, (2) selecting some appropriate activities and (3) making a checklist to know the activities that were performed during a weak and to integrate tasks for the intelligences that were neglected.

\section{Conclusion}

This study was conducted to investigate the impact of multiple intelligences on the DDL learning outcomes. The results obtained from the correlation analyses revealed that the identified predominant intelligences: mathematicallogical, visual-spatial and interpersonal intelligences were not significantly correlated with DDL vocabulary learning. This was confirmed by the multiple regression analyses which showed that the DDL vocabulary learning outcomes were not significantly predicted by these three intelligences. Such results might be due to the neglect of students' diverse needs while learning. Even though the three leading intelligences did not significantly contribute to the overall performance of the DDL group, the role of multiple intelligences in the EFL classroom particularly in designing DDL materials should not be neglected. A considerable amount of interest has been paid to the role of multiple intelligences in the EFL teaching and learning process (Biria et al. 2014, Oskooei \&Salahshoor 2014). The benefits derived from incorporating the multiple intelligence theory in the EFL pedagogy are not only associated with academic success. When identifying the multiple intelligence profiles of learners, teachers are provided with many ideas for designing learning activities tailored to meet learners' needs and potentials. Engaging in such activities promotes the active role of learners who use their unique abilities to demonstrate their learning. By doing so, an encouraging and motivating learning atmosphere is created (Masoomeh \& Mahdieh 2014). As far as the DDL method is concerned, the application of multiple intelligences theory directs teachers' attention to the importance of designing DDL activities to accommodate learners' diversities in learning. Designing learner-centered DDL classroom activities guided by learners' multiple intelligences profile could generate a more engaging learning environment that supports active learning and promotes high motivation.

The research had some limitations that are worthy of attention for future studies. The participants of the study were homogenous comprised of 60 female EFL Yemeni students. For the study findings to be generalized, a more diverse sample is needed. Moreover, this study was the first research attempts to assess the effects of multiple intelligences on DDL learning outcomes. Accordingly, the results of the study should be replicated by longitudinal future research that aims at increasing the activation of the three intelligences to provide more definitive evidence on the predictive effect of these intelligences on the learning gains achieved by DDL. As culture and background education have an effect on a person's intelligence profile, investigating the effect of the other intelligences different from the intelligences identified in this study on DDL could be usefully explored in further research.

\section{References}

Al Azri, R. H., \& Al-Rashdi, M. H. (2014). The effect of using authentic materials in teaching. International journal of scientific \& technology research, 3(10), 249-254.

Al- mahbashi, A., Noor, N. M., \& Amir, Z. (2015a). Learning diversity: multiple intelligences profile of Yemeni EFL university students. International Journal of Development Research, 5(12), 6380-6383.

Al-mahbashi, A., Noor, N. M., \& Amir, Z. (2015b). The Effect of Data Driven Learning on Receptive Vocabulary Knowledge of Yemeni University Learners. 3L: Southeast Asian Journal of English Language Studies, 21(3).

Alsied, S. M., \& Pathan, M. M. (2013). The use of computer technology in EFL classroom: advantages and implications. IJ-ELTS, 1(1), 61-71.

Bas, G. \& Beyhan, O. (2010). Effects of multiple intelligence supported project based learning on students' achievement levels and attitudes towards English lesson. International Electronic Journal of Elementary Education, 2(3).

Baum, S, Viens, J \& Slatin, B. (2005). Multiple intelligences in the elementary classroom: A teacher's toolkit. Teachers College Press, Columbia University.

Biber, D., S. Conrad \& R. Reppen (1998): Corpus Linguistics: Investigating Language Structure and Use. Cambridge: Cambridge University Press.

Biria, R; Boshrabadi, A., \& Nikbakht, E. (2014). The relationship between multiple intelligences and Iranian EFL learners' level of L2 lexical knowledge: The case of gender. Advances in Language and Literary Studies, 5 (3), 1-17. 
Boulton, A., \& Tyne, H. (2013). Corpus linguistics and data-driven learning: a critical overview. Bulletin suisse de Linguistique appliquée , 97, 97-118.

Boulton, A. (2011). Blending research methods: Qualitative and quantitative approaches to researching computer corpora for language learning. Proceedings of KAMALL 2011: New Directions for Blended Learning in EFL. Daejeon: Pai Chai University, South Korea.

Çelik, S. \& Elkatmiş, M. (2013). The Effect of Corpus Assisted Language Teaching on the

Learners' Proper Use of Punctuation Marks. Educational Sciences: Theory \& Practice, 13(2), 1090-1094.

Champers, A. (2010). What is data driven learning? In A. O'Keeffe \& M. McCarthy. The Routledge handbook of corpus linguistics (pp. 345-358). Routledge.

Chan, P-T. and H-C. Liou. (2005). Effects of web-based concordancing instruction on EFL students' learning of verbnoun collocations. Computer Assisted Language Learning, 18(3), 231-251.

Donesch-Jezo, E. (2013).Using Language Corpus in Teaching Foreign Language Vocabulary. International Multidisciplinary e-Journal, 2(1),11-25.

Dung, N. T., \& Tuan, L. T. (2011). Accommodating classroom activities to EFL learners' multiple intelligences. Mediterranean Journal of Social Sciences, 79.

Farahani, A. A. K., \& Kalkhoran, E. L. 2014. The relationship between incidental vocabulary learning and multiple intelligences of Iranian EFL learners. Theory and Practice in Language Studies, 4(1), 58.

Gan, Z. (2011) L2 Learner Individual Differences: An integrative and contextualist perspective. Reflections on English Language Teaching, 10 (1), 67-88.

Gardner, H. (1983). Frames of mind. New York: Basic books.

Ghadirian, S. (2002). Providing controlled exposure to target vocabulary through the screening and arranging of texts. Language Learning and Technology, 6, 147-164.

Johns, T. (1990). From printout to handout: Grammar and vocabulary teaching in the context of datadriven learning. CALL Austria,10, 14-34.

Jonassen, D. \& Grabowski, B. (2.11). Handbook of individual differences, learning, and instruction. Routledge.

Kutz, M., Dyer, S., \& Campbell, B. (2013). Multiple intelligence profiles of athletic training students. Internet Journal of Allied Health Sciences and Practice, 11(1), 9.

Lee, C-Y. and H-C. Liou. (2003). A study of using web concordancing for English vocabulary learning in a Taiwanese high school context. English Teaching and Learning, 27(3), 35-56.

Lujan-Ortega, V. and Clark-Carter, D. (2000). Individual differences, strategic performance and achievement in second language learners of Spanish. Studia Linguistica, 54(2), 280-287.

Mann, R. L. (2001). Eye to eye: Connecting with gifted visual-spatial learners. Gifted Child Today, 24(4), 54-57.

McEnery, T.\& Xiao, R. (2011). What corpora can offer in language teaching and learning. In E. Hinkel. Handbook of research in second language teaching and learning (pp. 364-380). Routledge.

McKenzie, W. (2002). Multiple intelligences and instructional technology: A manual for every mind. International Society for Technology in Education.

Moran, S., Kornhaber, M., \& Gardner, H. (2006). Orchestrating multiple intelligences. Educational Leadership,64(1), 22-27.

Muthanna, A., \& Karaman, A. C. (2011). The need for change in teacher education in Yemen: The beliefs of prospective language teachers.Procedia-Social and Behavioral Sciences, 12, 224-232.

Nation, I. S. P. (2005). Teaching and learning vocabulary. In E. Hinkel (Ed.), Handbook and research in second language teaching and learning (pp. 581-595). New Jersey: Lawrence Erlbaum.

Oghigian, K., \& Chujo, K. (2010). An effective way to use corpus exercises to learn grammar basics in English. Language Education in Asia, 1(1), 200-214.

O'Keeffe, A., \& McCarthy, M. (2010). The Routledge handbook of corpus linguistics. Routledge.

Oskooei, S, K., \&Salahshoor, F. (2014). The relationship between multiple intelligences and L2 reading skill among Iranian EFL university students. International Journal of Applied Linguistics \& English Literature , 3(5), 229-283.

Paribakht, T. \& Wesche, M. (1993). Reading comprehension and second language development in a comprehensionbased ESL program. TESL Canada Journal, 11(1), 9-29.

Rahimi, M., Mirzaei, A., \& Heidari, N. (2012). How do successful EFL readers bridge between multiple intelligences and reading strategies?. World Applied Sciences Journal,17(9), 1134-1142.

Saeidi, M. (2009). The implementation of multiple intelligence theory in the classroom: Different ways of learning and teaching. Journal of Teaching English as a Foreign Language and Literature, 1(1), 103-116. 
Tajeddin, Z., \& Chiniforoushan, N. (2011). Visual intelligence and lexical enhancement tasks: Their impacts of EFL learners' receptive and productive vocabulary. The Journal of Asia TEFL, 8(3), 109-134.

Talai, T. \& Fotovatnia, Z. (2012) Data- driven Learning: A student- centered technique for language learning. Theory and Practice in Language Studies, 2(7), 1526-1531.

Tian, S. (2005). Data-driven learning: Do learning tasks and proficiency make a difference. In Proceedings of the 9th Conference of the Pan-Pacific Association of Applied Linguistics. Tokyo: Waseda University Media Mix Corp (pp. 360-71).

Stockwell, G. (2007). A review of technology choice for teaching language skills in areas in the CALL literature. ReCALL Journal, 19(2), 105-120.

Sriphicharn, P. (2002). Introducing Data-Driven Learning: Theory, Practice, and Evaluation. Journal of Liberal Art, 2(2), 100-111.

Tajeddin, Z., \& Daraee, D. (2013). Vocabulary Acquisition through Written Input: Effects

of Form- Focused, Message- oriented, and Comprehension Tasks. The Electronic Journal for English as a Second Language, 16,1,13.

Zarei, A. A., \& Afshar, N. S. (2014). Multiple intelligences as predictors of reading comprehension and vocabulary knowledge. Indonesian Journal of Applied Linguistics, 4(1), 23-38. 